\title{
Internal mammary artery conduit: an additional surgical procedure in difficult coarctation of the aorta
}

\author{
UNNIKRISHNAN R NAIR, HENRI MOUSSALLI, DAVID C BETON \\ From the Regional Cardiothoracic Centre, Wythenshawe Hospital, Manchester
}

SUMMARY Between October 1986 and February 1987 two young men with coarctation of the aorta and a hypoplastic isthmus were treated by a combined resection and isthmusplasty with implantation of the left internal mammary artery to the distal aorta. An appreciable drop in the systolic gradient was seen in both patients after the mammary artery anastomosis and haemodynamic variables across the repair continued to improve postoperatively. Digital transvenous subtraction angiography five months after operation showed a satisfactory mammary artery conduit across the repaired coarctation.

The choice of operation for aortic coarctation is influenced by the patient's age, anatomical abnormality, and the surgeon's experience. ${ }^{12}$ Several different techniques have been described: resection and end to end anastomosis, subclavian flap aorto. plasty, patch aortoplasty with prosthetic or biological grafts, Vosschulte's aortoplasty, and prosthetic tubular conduit between the ascending and descending parts of the aorta. ${ }^{3-5}$ Severe hypoplasia of the isthmus in the adult patient may limit the extent of resection because in an attempt to maintain the collaterals to the spinal cord every effort is made to limit the number of intercostal vessels ligated or divided. A wider anastomosis may be achieved by isthmusplasty, but in severe cases of hypoplasia this alone may not reduce the systolic gradient to an acceptable value.

In these circumstances implantation of the left internal mammary artery to the distal aorta is a simple but effective additional procedure to achieve better flows beyond the repair.

\section{Case reports}

PATIENT 1

A 27 year old symptom free man was found to have a coarctation of the aorta at a routine medical examina-

Requests for reprints to Mr Unnikrishnan R Nair, FRCS, Department of Cardiothoracic Surgery, Wythenshawe Hospital, Southmoor Road, Manchester M23 9LT.

Accepted for publication 26 October 1987 tion. Blood pressure recordings showed a systolic gradient of $90 \mathrm{~mm} \mathrm{Hg} \mathrm{(170/110} \mathrm{in} \mathrm{the} \mathrm{arm} \mathrm{and} \mathrm{80/40}$ in the leg). A tight coarctation with hypoplastic aorta was confirmed at aortography. At operation, through a left thoracotomy, the coarctation was excised and repair effected by isthmusplasty. The systolic gradient fell from $90 \mathrm{~mm} \mathrm{Hg}$ to $30 \mathrm{~mm} \mathrm{Hg}$. The left internal mammary artery was therefore dissected off the chest wall and the distal end was anastomosed to the distal aorta with 50 Prolene sutures over a side clamp on the aorta. The internal diameter of the internal mammary artery was $10 \mathrm{~mm}$ and the final gradient across the repair was $9 \mathrm{~mm} \mathrm{Hg}$.

Paradoxical hypertension developed immediately after operation; this responded to $\beta$ blockade. His recovery was otherwise uneventful and the arm to leg systolic gradient had disappeared on subsequent examination eight days after operation. His condition was entirely satisfactory at an outpatient review four months later. Patency of the internal mammary artery was confirmed by digital transvenous subtraction angiography five months after the repair (figure).

\section{PATIENT 2}

A 28 year old symptom free man was found to have coarctation of the aorta at a routine medical check up. His aortogram showed a coarctation of a long segment and hypoplasia of the isthmus, with a systolic pressure gradient of $65 \mathrm{~mm} \mathrm{Hg}$ across the coarctation. At operation, through a left thoracotomy, the repair was effected by resection of the coarctation and isthmusplasty, and the systolic pressure gradient fell to $41 \mathrm{~mm} \mathrm{Hg}$. The left internal mammary artery, which had an internal diameter of $6 \mathrm{~mm}$, was 


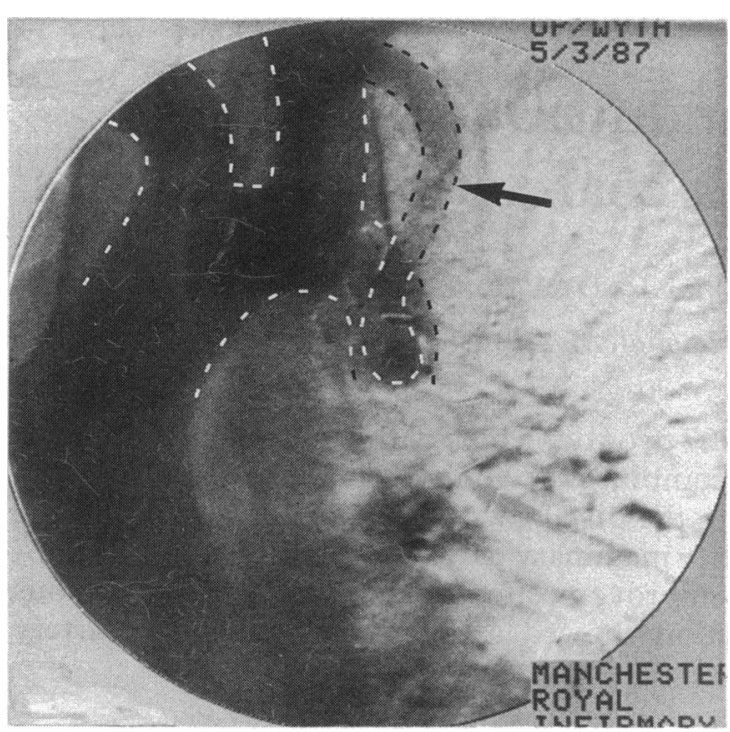

Figure Transvenous digital subtraction angiogram showing the internal mammary artery conduit across the site of the repaired coarctation.

dissected off the chest wall and implanted on to the distal aorta with $5 \mathrm{O}$ Prolene sutures by means of a side clamp on the aorta. Subsequent recordings showed a systolic gradient of $20 \mathrm{~mm} \mathrm{Hg}$. This patient developed paradoxical hypertension, which responded to $\beta$ blockers. The arm to leg systolic gradient was $<10 \mathrm{~mm} \mathrm{Hg}$ before his discharge nine days after operation.

\section{Discussion}

The object of any corrective operation for aortic coarctation is a zero gradient across the repair. There are no absolute guidelines, but most surgeons regard a systolic gradient of $<20 \mathrm{~mm} \mathrm{Hg}$ in an adult or 10 $\mathrm{mm} \mathrm{Hg}$ in a child as acceptable. ${ }^{6-8}$ In a series of cases of recurrent coarctation, Sweeny et al considered an arm to leg systolic gradient of $\geqslant 30 \mathrm{~mm} \mathrm{Hg}$ as an indication for reoperation. ${ }^{9}$

Ischaemic injury to the spinal cord is a known complication of operation for coarctation, and this is more common in reoperations. ${ }^{210}$ Even though no definite correlation has been established between the extent of spinal cord ischaemia and the number of intercostal arteries divided, most surgeons believe that every effort should be made to achieve an adequate anastomosis with division of as few intercostal vessels as possible. Other factors that influence damage of the spinal cord include the anatomical abnormalities of the anterior spinal artery and the duration of aortic cross clamping.

A relatively small aorta and the proximity of large
(

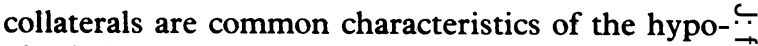
plastic isthmus. Resection of the abnormal tissue of coarctation may be justified in an attempt to prevent $-\overrightarrow{0}$ recurrence. Isthmusplasty will increase the effective $\overline{0}$ diameter of the anastomosis. In severe hypoplasia, $\overline{\bar{\sigma}}$ however, the final gradient may still remain high $\widehat{\Phi}$ because the size of the anastomosis is limited. The systolic gradients after isthmusplasty in our two ${ }^{\infty}$ patients were 30 and $40 \mathrm{~mm} \mathrm{Hg}$ respectively. The. large left internal mammary artery was therefore $\vec{\overrightarrow{ }}$ dissected off the chest wall and implanted to the distal ${ }_{\sigma}^{\omega}$ aorta in both patients; this reduced the systolic gradient to $9 \mathrm{~mm} \mathrm{Hg}$ and $20 \mathrm{~mm} \mathrm{Hg}$ respectively, indicating better flows beyond the site of repair.

Use of the internal mammary artery as a free patch $\omega$

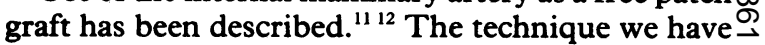
described has the advantages of a relatively easy음 anastomosis over a side clamp and of a very large and convenient collateral being used as a conduit. We 3 must emphasise, however, that this technique is unsuitable for young patients with coarctation $\supset$ because their internal mammary arteries are small. $\overrightarrow{0}$ The fragility of the intercostal vessels in aortic $\infty$ coarctation is well known. We noticed that even 0 though these vessels had aneurysmal dilatation at their origin from the aorta, they were of remarkably good quality where they communicated with the internal mammary artery. These communications $\frac{\circ}{\varnothing}$ were divided between Ligaclips and then each end $\stackrel{2}{\Rightarrow}$ was reinforced with 60 Prolene sutures for added 0 safety. We found that vessel wall hypertrophy of the $\frac{J}{\vec{T}}$ dilated mammary artery made it safe to anastomose to the aorta. We were quite satisfied with the condition of the mammary artery as visualised on the $\vec{\Phi}$ digital transvenous subtraction angiogram (figure). Caution should, however, be exercised if this patient has a left lung resection in later years because of the position of the mammary artery in relation to the left $\delta$ hilum.

We recommend the implantation of the left inter- $\frac{\text { ? }}{2}$ nal mammary artery to the distal aorta in adults with $D$ coarctation and a hypoplastic isthmus if the systolic gradient remains $\geqslant 30 \mathrm{~mm} \mathrm{Hg}$ after the repair. It is $\tilde{\Omega}$ simple but effective and does not increase morbidity because the anastomosis can be constructed without 0 cross clamping of the aorta.

We thank Dr Richard Fawcett for his kind assistance with the investigations.

\section{References}

1 Jamieson SW, Shumway NE. Cardiac surgery. In: Dudley H, Carter D, eds. Rob E Smith's operative $\frac{\mathbb{D}}{\mathrm{D}}$ surgery. 4th ed. London and Glasgow: Butterworths,
1986:371-80.

2 Starr A, Harwin FM. Manual of cardiac surgery. Vol 1. 
2nd ed. New York: Futura, 1984:170-84.

3 Crawfoord C, Nylin G. Congenital coarctation of the aorta and its surgical treatment. $J$ Thorac Surg 1945; 14:347-61.

4 Waldhausen JA, Nahrwold DL. Repair of coarctation of the aorta with subclavian flap. J Thorac Cardiovasc Surg 1966;51:532-3.

5 King H, Kaisser G, King R. Repair of coarctation of the aorta by patch grafting. J Thorac Cardiovasc Surg 1962;43:792-5.

6 Lerberg DB, Hardesty RL, Siewers RD, Zuberbuhler JR, Bahnson HT. Coarctation of the aorta in infants and children: 25 years of experience. Ann Thorac Surg 1982;33:159-70.

7 Palatianos GM, Kaiser GA, Thurer RJ, Garcia O. Changing trends in the surgical treatment of coarctation of the aorta. Ann Thorac Surg 1985;40:41-5.

8 Metzdorff MT, Cobanglu A, Grunkemeier GL,
Sunderland CO, Starr A. Influence of age at operation on late result with subclavian flap aorto-plasty. $J$ Thorac Cardiovasc Surg 1985;89:235-41.

9 Sweeny MS, Walker WE, Duncan JM, Hallman GL, Livesay JJ, Cooley DA. Re-operation for aortic coarctation: techniques, results and indications for various approaches. Ann Thorac Surg 1985;40:46-9.

10 Brewer LA, Fosburg RG, Mulder GA, et al. Spinal cord complications following surgery for coarctations of the aorta: a study of 66 cases. $J$ Thorac Cardiovasc Surg 1972;64:368-81.

11 Moore GF, Ionescu MI, Ross DN. Surgical repair of coarctations of the aorta by patch grafting. Ann Thorac Surg 1972;14:626-30.

12 Compalani G, Firmin RK, Vaughan M, Ross DN. Surgical repair of coarctations of the aorta using the internal mammary artery as a free autogenous graft. $J$ Thorac Cardiovasc Surg 1985;90:928-31. 